\title{
Morfometria radicular de Moringa oleifera em função do pré-tratamento de sementes com luz e extrato de tiririca
}

\author{
Kaline de Souza Meira ${ }^{l}$, Alexandre Eugênio da Silva ${ }^{l}$, João Paulo Avelon ${ }^{l}$, Patrícia da Silva Costa ${ }^{2}$, Rener Luciano de \\ Souza Ferraz $*^{l}$, Antônio Manoel da Silva Filho ${ }^{l}$. \\ ${ }^{1}$ Universidade Estadual da Paraíba, kalinemeira@hotmail.com, eugeniodasilvaalexandre@gmail.com; \\ jpaulotecnicoagricola@ hotmail.com, ferragroestat@gmail.com, antoniouepb@gmail.com, ${ }^{2}$ Universidade Federal de \\ Campina Grande, patriciagroambiental@gmail.com.
}

\begin{abstract}
RESUMO: Maior demanda por alimentos para garantia de segurança alimentar da população impulsiona o cultivo de plantas com potencial para múltiplos usos. Assim, objetivou-se avaliar a morfometria radicular de Moringa oleifera em função do pré-tratamento de sementes com luz e extrato de tiririca. A pesquisa foi realizada entre os meses de outubro e dezembro de 2018, no Laboratório de Fitopatologia pertencente ao Centro de Ciências Agrárias e Ambientais da Universidade Estadual da Paraíba, localizado no município de Lagoa Seca - PB. Utilizou-se delineamento inteiramente casualizado, em esquema fatorial $4 \mathrm{x} 4$, sendo quatro condições de luminosidade (luz branca, azul, vermelha e vermelho extremo) e quatro concentrações de extrato aquoso de tubérculos de tiririca $(0,25,50$ e $100 \%)$. As avaliações consistiram na medição do comprimento inicial da raiz, comprimento final da raiz e taxa de crescimento relativo da raiz. Para realização das análises foi utilizado o software Sisvar 5.6. A rizogênese da M. oleifera foi bioinduzida pelo pré-tratamento de sementes com luz vermelha, não sendo recomendada a aplicação de extrato aquoso de tubérculo de tiririca. As informações geradas nesta pesquisa são de fundamental importância para o incremento do arcabouço tecnológico acerca do aumento da eficiência produtiva da M. Oleifera.
\end{abstract}

PALAVRAS-CHAVE: Germinação; Qualidade de luz; Hormônios vegetais; Moringaceae.

\section{INTRODUÇÃO}

Segundo a Organização das Nações Unidas para Agricultura e Alimentação (FAO), estima-se que, atualmente, 815 milhões de pessoas sofram de desnutrição (CICERI; ALLANORE, 2019). A demanda por recursos está projetada para aumentar na medida em que a população cresça até 2050, o que requer aumentos de 55\% na disponibilidade de água, 60\% de alimentos e $80 \%$ de energia (DAHER et al., 2019).

Alterações nas variáveis do clima como temperatura e luminosidade, podem influenciar a germinação de sementes e desenvolvimento de plantas, notadamente devido às variações na qualidade da luz e sua relação com os fotorreceptores vegetais (BORNMAN et al., 2019; WEBER et al., 2019). Uma estratégia para garantia de sustentabilidade e segurança alimentar é o cultivo de plantas com potencial para múltiplos usos, com plasticidade genotípica e fenotípica para adaptação aos mais variados agroecossistemas de cultivo, como em sistemas de integração lavoura-pecuária-floresta (BUSSONI et al., 2019; CORTNER et al., 2019). Nesse contexto, a Moringa oleifera Lamark tem ganhado destaque mundialmente, uma vez que todas as partes da planta podem ser usadas como alimentos, medicamentos e para fins industriais (LIU et al., 2018).

A M. oleifera é uma espécie da família Moringaceae, nativa da Índia e do Paquistão (DOMENICO; LINA; FRANCESCA, 2019), sendo cultivada em regiões áridas e semiáridas, caracterizando-se em alternativa para alimentação humana e animal devido seu potencial nutritivo, além de possuir aminoácidos essenciais macro e micronutrientes (KARTHICKEYAN, 2019; PÁRAMO-CALDERÓN et al., 2019). A disponibilidade, qualidade e tempo de exposição à luz é primordial para a germinação de sementes, de modo que $M$. oleifera responde às variações luminosas, sobretudo devido ao fato da luz influenciar em outros fatores como temperatura e umidade do solo, ar e planta (AHMED et al., 2014).

A percepção da luz pelos fotorreceptores tem papel decisivo nos processos fisiológicos das plantas. Transduções de sinais luminosos envolvem eventos bioquímicos importantes para biossíntese e ação de hormônios vegetais responsáveis pelas mudanças fotomorfogenéticas e tolerância aos estresses abióticos (MATSUO et al., 2019; POLESI et al., 2019; VAISHAK et al., 2019). Ressalta-se que os hormônios vegetais (fitohormônios), como auxinas, giberelinas, citocininas, ácido abscísico, etileno, brassinosteróides e estrigolactonas regulam a germinação, o crescimento e desenvolvimento das plantas (PAWELA et al., 2019; PERES et al., 2019). Estes hormônios podem ser obtidos de fontes sintéticas e naturais, como por exemplo, o ácido-3-indolbutírico (auxina) presente em tubérculos de tiririca (Cyperus rotundus L.) que pode ser utilizado como tecnologia para promoção de quebra de dormência e germinação de sementes (RIFNA et al., 2019).

A germinação de sementes é um processo fisiológico complexo que começa com a absorção de água e termina com a protrusão da radícula (TUAN et al., 2019). Neste contexto, o pré-tratamento (priming) de sementes consiste em controlar o teor de água das sementes para ativar parcialmente os processos de germinação, como o metabolismo, mas evita a germinação total, retornando as sementes ao estado de quiescência (SANO; SEO, 2019).

Caderno Verde de Agroecologia e Desenvolvimento Sustentável (ISSN 2358-2367) v. 9, n.7, e-7058, 2019 doi: $10.18378 /$ cvads.v9i7.7058 
MEIRA, K. S. et al. Morfometria radicular de Moringa oleifera em função do pré-tratamento de sementes com luz e extrato de tiririca. In: II Congresso Paraibano de Agroecologia \& IV Exposição Tecnológica, 2019. Anais... Caderno Verde de Agroecologia e Desenvolvimento Sustentável, Pombal, v. 9, n.7, e-7058, 2019.

Com base no exposto, pode-se inferir a hipótese de que à bioindução a partir de priming aplicado nas sementes com diferentes condições de luminosidade e doses de extratos de tiririca, irá influenciar a germinação. Assim, objetivou-se avaliar a morfometria radicular de Moringa oleifera em função do pré-tratamento de sementes com luz e extrato de tiririca.

\section{MATERIAL E MÉTODOS}

A pesquisa foi realizada entre os meses de outubro e dezembro de 2018, no Laboratório de Fitopatologia e em ambiente telado pertencente ao Centro de Ciências Agrárias e Ambientais (CCAA) da Universidade Estadual da Paraíba (UEPB), localizado no município de Lagoa Seca - PB.

Para aplicação do priming visando à germinação, foram utilizadas sementes comerciais de M. oleifera, obtidas da safra 2018, lote 00016 da empresa Arbocenter. Inicialmente, as sementes passaram pelo processo de assepsia com hipoclorito de sódio a 1\%, por 3 min (CARVALHO; CARVALHO, 2009), realizado sob luz verde, tida como luz de segurança, sem influência sobre os fitocromos (PEREIRA et al., 2011).

$\mathrm{O}$ experimento foi conduzido em delineamento inteiramente casualizado, em esquema fatorial $4 \mathrm{x} 4$, com quatro repetições de 24 sementes (PEREIRA et al., 2015). Os fatores consistiram de quatro condições de luminosidade (LBR = luz branca com emissão de $10 \mu \mathrm{mol} \mathrm{m}-2 \mathrm{~s}-1$, LAZ = luz azul com comprimentos de onda de $400 \mathrm{a} 485 \mathrm{~nm}$, LVE = luz vermelha com comprimento de onda de 600 a $680 \mathrm{~nm}$ e LVX = luz vermelho extremo com comprimento de onda de 680 a $720 \mathrm{~nm})$ e quatro concentrações de extratos exógenos $($ EAT0 $=$ controle $0 \%$, EAT25 $=25 \%$, EAT50 = 50\% e EAT $100=100 \%$ de extrato aquoso de tubérculos de $C$. rotundus L.).

As sementes foram alocadas em caixas plásticas, tipo gerbox, medindo 11x11x3,5 cm de comprimento, largura e altura, respectivamente. Para obtenção da luz branca; azul e vermelha, foram utilizadas caixas plásticas transparentes, revestidas com quatro camadas de papel celofane com suas respectivas cores, e para o vermelho extremo, o revestimento foi com duas camadas de papel celofane vermelho e duas de azul, sobrepostas (YAMASHITA; GUIMARAES; CAVENAGHI, 2011).

Tubérculos de $C$. rotundus foram obtidos no campo experimental do CCAA/UEPB em uma área com infestação severa. Para obtenção do extrato aquoso de $C$. rotundus, os tubérculos frescos foram isolados, lavados com água e detergente neutro, secos em papel toalha e pesados. Foram utilizados 10,0 g de tubérculos, os quais foram triturados em liquidificador com $200 \mathrm{ml}$ de água destilada e peneirados, para obtenção de uma solução estoque com 100\% do extrato (SIMÕES et al., 2003).

Em cada caixa, o substrato foi constituído de duas camadas de folha de papel 'germitex' umedecidas com as soluções correspondentes a cada tratamento, em volume correspondente a aproximadamente 2,5 vezes a sua massa seca (FERREIRA et al., 2017). As caixas contendo as sementes foram acondicionadas em câmara germinadora tipo Biochemical Oxigen Demand (B.O.D.), regulada na temperatura de $30 \pm 5^{\circ} \mathrm{C}$, com fotoperíodo de 8 horas (PEREIRA et al., 2015).

O tempo de aplicação do priming foi de $24 \mathrm{~h}$, período necessário para embebição das sementes na fase de ativação metabólica (fase II) sem que haja a conclusão do processo de germinação (GUIMARÃES; DIAS; LOUREIRO, 2008). Posteriormente, as sementes foram colocadas para secar durante $24 \mathrm{~h}$ em bandejas de polietileno com dimensões de $30 \mathrm{~cm}$ x $20 \mathrm{~cm}$ × $5 \mathrm{~cm}$ de comprimento, largura e altura, respectivamente, as quais foram revestidas com duas camadas de papel absorvente e cobertas com papel celofane nas cores correspondentes às mesmas condições de luminosidade utilizadas durante a aplicação do priming.

Para avaliação da germinação, as sementes utilizadas no priming foram semeadas na profundidade aproximada de $0,02 \mathrm{~m}$ em bandejas de polietileno, preenchidas com 3,0 kg de substrato arenoso autoclavado, com umidade mantida entre 90 e $100 \%$ da capacidade de campo (CC). As bandejas foram alocadas em ambiente telado com redução de $15 \%$ da luminosidade.

O manejo da irrigação foi diariamente realizado em turno de rega de $24 \mathrm{~h}$, utilizando-se do método de pesagens, em que foi reposta a água evapotranspirada nas 24 h que antecederam cada evento de irrigação.

Para reposição do volume de água requerida, utilizou-se de proveta graduada em mililitros (mL) com capacidade volumétrica para $300 \mathrm{~mL}$. Para as pesagens, utilizou-se de balança digital portátil, modelo 123 Util, com precisão de 0,00 g, alimentada com pilhas do tipo AAA (SILVA et al., 2019).

As avaliações consistiram na medição do comprimento inicial da raiz (CIR, em $\mathrm{cm})$, comprimento final da raiz (CFR, em cm) e taxa de crescimento relativo da raiz (TCRR, em cm- 1 dia-1) (FERRAZ et al., 2017).

Transcorridos 13 dias, a contar da implantação do experimento, foram selecionadas duas plântulas uniformes por parcela, nas quais foram realizadas medições para determinação do comprimento inicial da raiz (CIR), o qual foi aferido utilizando-se de régua graduada em mm. (FERRAZ et al., 2017). Transcorridos 21 dias de implantação do experimento, dentre as plântulas remanescentes, foram selecionadas duas por parcela, nas quais foram realizadas medições para determinação do comprimento médio final da raiz (CFR) e taxa de crescimento relativo da raiz (TCRR) (FERRAZ et al., 2017).

Os dados das variáveis de resposta foram submetidos ao teste de normalidade de Shapiro-Wilk (SHAPIRO; WILK, 1965). Atendidos os pressupostos de normalidade, foi realizada análise de variância pelo teste $\mathrm{F}$ com $95 \%$ de confiança. Para o desdobramento dos graus de liberdade das condições de luminosidade foi aplicado teste de 
MEIRA, K. S. et al. Morfometria radicular de Moringa oleifera em função do pré-tratamento de sementes com luz e extrato de tiririca. In: II Congresso Paraibano de Agroecologia \& IV Exposição Tecnológica, 2019. Anais... Caderno Verde de Agroecologia e Desenvolvimento Sustentável, Pombal, v. 9, n.7, e-7058, 2019.

comparações múltiplas de médias (Tukey) ao nível de 5\% de probabilidade de erro, enquanto que para as concentrações de extrato aquoso de $C$. rotundus foi realizada análise de regressão polinomial e a escolha dos modelos determinada pela significância dos parâmetros de regressão (BARBOSA; MALDONADO JÚNIOR, 2015). Para realização das análises foi utilizado o software Sisvar 5.6 (FERREIRA, 2014).

\section{RESULTADOS E DISCUSSÃO}

Verificou-se que as condições de luminosidade promoveram diferença significativa no comprimento final da raiz (CFR), enquanto que comprimento inicial da raiz (CIR) e taxa de crescimento relativo da raiz (TCRR) não foram influenciados significativamente pela luz. O extrato aquoso de tubérculos de tiririca não teve efeito significativo nas variáveis, CIR; CFR e TCRR.

Houve interação significativa entre as condições de luminosidade e as concentrações de extrato para a variável CFR, enquanto que as demais variáveis não foram influenciadas pela interação entre estes fatores (Tabela 1).

Tabela 1. Resumo das análises de variância para germinação e crescimento inicial de Moringa oleifera sob variação espectral de luz e extrato aquoso de tubérculos de tiririca.

\begin{tabular}{|c|c|c|c|c|}
\hline \multirow[t]{2}{*}{ Fontes de Variação } & \multirow[t]{2}{*}{ GL } & \multicolumn{3}{|c|}{ Quadrados médios } \\
\hline & & CIR & CFR & TCRR \\
\hline Luz (L) & 3 & $1,68^{\mathrm{ns}}$ & $2,48^{*}$ & $18 \mathrm{e}-3^{\mathrm{ns}}$ \\
\hline Extratos $(\mathrm{E})$ & (3) & $0,66^{\mathrm{ns}}$ & $0,34^{\mathrm{ns}}$ & $65 \mathrm{e}-4^{\mathrm{ns}}$ \\
\hline Regressão Linear & 1 & $0,01^{\mathrm{ns}}$ & $0,56^{\mathrm{ns}}$ & $94 \mathrm{e}-5^{\mathrm{ns}}$ \\
\hline Regressão Quadrática & 1 & $1,90^{\mathrm{ns}}$ & $0,46^{\mathrm{ns}}$ & $11 \mathrm{e}-3^{\mathrm{ns}}$ \\
\hline Desvio da Regressão & 1 & $0,05^{\mathrm{ns}}$ & $21 e-3^{\text {ns }}$ & $67 e-4^{\mathrm{ns}}$ \\
\hline Interação L x E & 9 & $1,07^{\mathrm{ns}}$ & $2,03^{*}$ & $64 \mathrm{e}-4^{\mathrm{ns}}$ \\
\hline Resíduo & 48 & 0,82 & 0,80 & $74 \mathrm{e}-4$ \\
\hline $\mathrm{CV}(\%)$ & & 21,98 & 16,16 & 80,29 \\
\hline
\end{tabular}

Fonte: Elaboração do autor, 2019.

Essas diferenças significativas podem ser atribuídas ao fato de as plantas de $M$. oleifera possuírem fotorreceptores, como fitocromos, criptocromos e fototropinas, que absorvem espectros de luz específicos e criam sinais para modular a expressão gênica por meio de sistemas de transdução de sinais em células de plantas. Além disso, a qualidade da luz pode ter afetado os níveis de fitormônios contidos no extrato de tiririca, como auxinas, giberelina e citocininas, através da expressão gênica associada à regulação metabólica e isso pode ter alterado a síntese de metabólitos secundários pelos sinais dos fotorreceptores e ocasionado redução na rizogênese (FUKUDA, 2019).

Com relação ao comprimento final da raiz (CFR), verificou-se que maior valor $(6,68 \mathrm{~cm})$ em plântulas de $M$. oleifera foi obtido sob priming de sementes com aplicação de $25 \%$ de EAT e luz branca, diferindo do CFR de 4,56 cm registrado sob luz azul. Quando as sementes foram submetidas em concentrações com 50\% de EAT, maior CFR (6,38 $\mathrm{cm}$ ) foi obtido sob vermelho extremo, diferindo dos 4,65 $\mathrm{cm}$ medidos nas plântulas oriundas de sementes submetidas à luz azul (Figura 1A).

O incremento das concentrações de extratos associado à luz branca durante a bioindução promoveu redução de 29,7\% no CFR quando foram comparados os valores de $6,50 \mathrm{~cm}$ obtidos de plântulas oriundas de sementes não tratadas com EAT (0\%) e os 4,57 cm medidos nas plântulas geradas de sementes tratadas com 100\% de EAT (Figura 1B).

Figura 1. Comprimento final da raiz (CFR) de plântulas de M. oleifera em função do desdobramento de luz dentro de extrato (A) e concentrações de extrato dentro da luz branca (B).
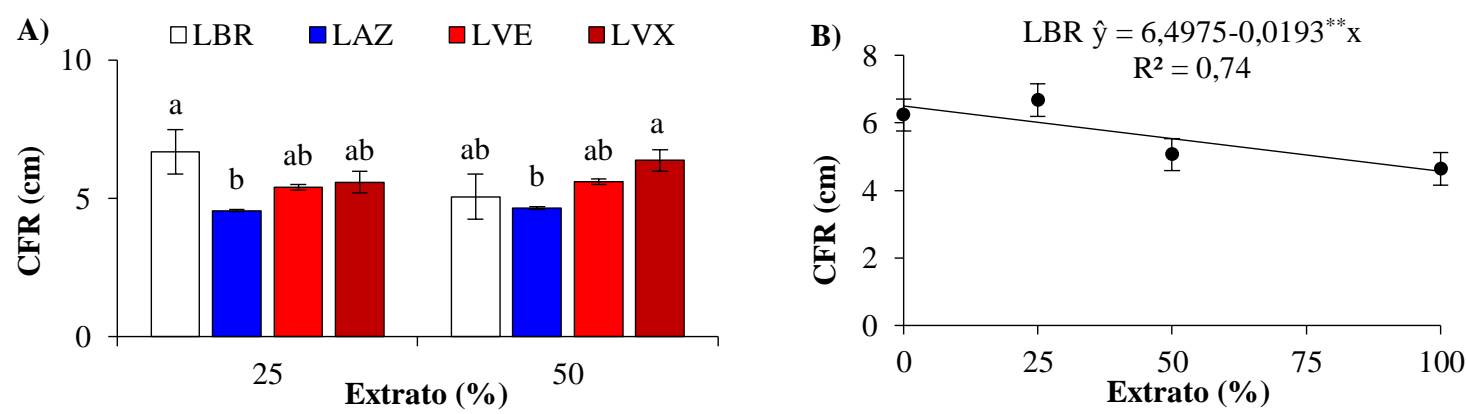

Neste contexto, o uso de luz branca pode ter ativado a fotopercepção e desencadeado respostas adaptativas para maior taxa de crescimento das plântulas de M. oleifera. Embora comprimentos de onda na região do azul (400-500 nm) e vermelho $(600-700 \mathrm{~nm})$ do espectro visível sejam mais eficientes para a captura de CO2 e liberação de O2, é 
MEIRA, K. S. et al. Morfometria radicular de Moringa oleifera em função do pré-tratamento de sementes com luz e extrato de tiririca. In: II Congresso Paraibano de Agroecologia \& IV Exposição Tecnológica, 2019. Anais... Caderno Verde de Agroecologia e Desenvolvimento Sustentável, Pombal, v. 9, n.7, e-7058, 2019.

importante ressaltar que o aumento significativo verificado no CFR sob luz branca e extrato de tiririca pode estar relacionado ao fato de que até $50 \%$ da composição espectral da luz branca está situada entre 500 e $600 \mathrm{~nm}$, abrangendo as luzes azul, verde, amarelo, vermelho e vermelho extremo (MICKENS et al., 2018).

A redução do CFR oriundas de sementes submetidas ao priming com luz azul (LAZ) evidencia o papel fundamental da luz no processo de germinação e crescimento de raízes de plântulas de $M$. oleifera, isso sugere que a fotomorfogênese desta espécie é regulada por um conjunto de fotorreceptores para percepção do sinal luminoso, os fitocromos (KAMI et al., 2010; NEFF, 2012).

Na prática, possivelmente, o maior CFR se deva ao fato do priming com a LVX ter ativado os fitocromos phyA, phyB, phyC, phyD e phyE, pois estes fotorreceptores são responsáveis pela percepção e modulação da luz e a expressão gênica por meio de sistemas de transdução de sinais (OKA; YAMAMOTO, 2019).

Sob luz branca (LBR) associada às concentrações de extrato, houve a redução do CFR, o que pode ter ocorrido devido ao fato da luz influenciar o processo de germinação e crescimento inicial da raiz de $M$. oleifera, pois a ação dos reguladores de crescimento vegetal endógenos pode ser incrementada pela utilização de extrato de tiririca, uma vez que as plantas sintetizam auxinas que, quando utilizadas em quantidade supra ótimas, podem ter efeito herbicida e reduzirem o crescimento, assim como observado sob luz branca (LV et al., 2018; BIELESZOVÁ et al., 2019).

As informações geradas nesta pesquisa são de fundamental importância para incremento do arcabouço tecnológico acerca do aumento da eficiência produtiva da M. oleifera, notadamente devido ao fato da bioindução por mudanças no espectro de luz e concentrações de extrato de tiririca proporcionar maior adaptabilidade desta espécie aos agroecossistemas, sobretudo na região Nordeste do Brasil.

\section{CONCLUSÕES}

A morfometria radicular de Moringa oleifera sob luz teve efeito no comprimento final da raiz (CFR), sendo recomendado concentrações de 50\% de extrato de tiririca, submetidos a luminosidade vermelho extremo.

\section{REFERÊNCIAS}

AHMED, L. T.; WARRAG, E. I.; ABDELGADIR, A. Y. Effect of Shade on Seed Germination and Early Seedling Growth of Moringa Oleifera Lam. Journal of Forest Products \& Industries, Bahri, v. 3, n. 1, p. 20-26, 2014.

BARbOSA, J. C.; MALDONADO JÚNIOR, W. Experimentação Agronômica \& AgroEstat Sistema para Análises Estatísticas de Ensaios Agronômicos. Funep, 2015.

BIELESZOVÁ, K. et al. New fluorescently labeled auxins exhibit promising anti-auxin activity. New Biotechnology, Netherlands, v. 48, p. 44-52, 2019.

BORNMAN, J. F. et al. Linkages between stratospheric ozone, UV radiation and climate change and their implications for terrestrial ecosystems. Photochemical \& Photobiological Sciences, London, p. 681-716, 2019.

BUSSONI, A. et al. Diverse strategies for integration of forestry and livestock production. Agroforestry Systems, Amsterdã, v. 93, p. 333-344, 2019.

CARVALHO, D. B.; CARVALHO, R. I. N. Qualidade fisiológica de sementes de guanxuma em influência do envelhecimento acelerado e da luz. Acta Scientiarum. Agronomy, Maringá, v. 31, n. 3, p. 489-494, 2009.

CICERI, D.; ALLANORE, A. Local fertilizers to achieve food self-sufficiency in Africa. Science of The Total Environment, Amsterdã, v. 648, p. 669-680, 2019.

CORTNER, O. et al. Perceptions of integrated crop-livestock systems for sustainable intensification in the Brazilian Amazon. Land Use Policy, Amsterdã, v. 82, p. 841-853, 2019.

DAHER, B. et al. Toward creating an environment of cooperation between water, energy, and food stakeholders in San Antonio. Science of The Total Environment, Amsterdã, v. 651, n. 2, p. 2913-2926, 2019.

DOMENICO, M.; LINA, C.; FRANCESCA, B. Sustainable Crops for Food Security: Moringa (Moringa oleifera Lam.). Encyclopedia of Food Security and Sustainability, Amsterdã, v. 1, p. 409-415, 2019.

ECHER, F. R. et al. Estresse hídrico induzido por manitol em cultivares de algodão. Revista Ciência Agronômica, Fortaleza, v. 41, n. 4, p. 638-645, 2010.

FERRAZ, R. L. S. et al. Atributos qualitativos de sementes de algodoeiro hidrocondicionadas em soluções de silício. 
MEIRA, K. S. et al. Morfometria radicular de Moringa oleifera em função do pré-tratamento de sementes com luz e extrato de tiririca. In: II Congresso Paraibano de Agroecologia \& IV Exposição Tecnológica, 2019. Anais... Caderno Verde de Agroecologia e Desenvolvimento Sustentável, Pombal, v. 9, n.7, e-7058, 2019.

Científica, São Paulo, v. 45, n. 1, p. 85-94, 2017.

FERREIRA, D. F. Sisvar: a Guide for its Bootstrap procedures in multiple comparisons. Ciência e Agrotecnologia, Lavras, v. 38, n. 2, p. 109-112, 2014.

FERREIRA, D. T. R. G. et al. Germinação de três Euphorbiaceae influenciada pela luz e níveis de palhada. Revista Agro@mbiente On-line, Cauamé, v. 11, n. 3, p. 215-222, 2017.

FUKUDA, N. Plant growth and physiological responses to light conditions author links open overlay panel. In: ANPO M, FUKUDA H, WADA T, editors. Plant Factory Using Artificial Light: Adapting to Environmental Disruption and Clues to Agricultural Innovation. Elsevier; 2019.

GUIMARÃES, M. A.; DIAS, D. C. F. S.; LOUREIRO, M. E. Hidratação de sementes. Revista Trópica - Ciências Agrárias e Biológicas, Chapadinha, v. 2, n. 1, p. 31-39, 2008.

KAMI, C. et al. Light-Regulated Plant Growth and Development. In: LITSCHER, E. S.; WASSARMAN, P. M. (Ed.). Current Topics in Developmental Biology. Elsevier: Amsterdã, p. 29-66, 2010.

KARTHICKEYAN, V. Effect of cetane enhancer on Moringa oleifera biodiesel in a thermal coated direct injection diesel engine. Fuel, London, v. 235, p. 538-550, 2019.

KONG, Y. et al. Blue light associated with low phytochrome activity can promote elongation growth as shadeavoidance response: A comparison with red light in four bedding plant species. Environmental and Experimental Botany, Elmsford, v. 155, p. 345-359, 2018.

LIU, Y. Light quality affects flavonoid production and related gene expression in Cyclocarya paliurus. Journal of Photochemistry and Photobiology B: Biology, Lausanne, v. 179, p.66-73, 2018.

LV, B. et al. Local auxin biosynthesis mediates plant growth and development. Trends in Plant Science, Oxford, 2018. (In Press).

MATSUO, S. et al. Effects of Blue and Red Lights on Gibberellin Metabolism in Tomato Seedlings. The Horticulture Journal, Yamaguchi, v. 88, n. 1, p. 76-82, 2019.

MICKENS, M. A. et al. A strategic approach for investigating light recipes for 'Outredgeous' red romaine lettuce using white and monochromatic LEDs. Life Sciences in Space Research, New York, v. 19, p. 53-62, 2018.

NEFF, M. M. Light-Mediated Seed Germination: Connecting Phytochrome B to Gibberellic Acid. Developmental Cell, Cambridge, v. 22, n. 4, p. 687-688, 2012.

OKA, Y.; YAMAMOTO, K. Photoreceptor-Mediated Plant Development. In: ANPO, M.; FUKUDA, H.; WADA, T. (Ed.). Plant Factory Using Artificial Light: Adapting to Environmental Disruption and Clues to Agricultural Innovation. Elsevier: Amsterdã, p. 111- 117, 2019.

PÁRAMO-CALDERÓN, D. E. et al. Tortilla added with Moringa oleifera flour: Physicochemical, texture properties and antioxidant capacity. LWT, Athens, Georgia, v. 100, p. 409-415, 2019.

PAWELA, A. et al. Mt ABCG 20 is an ABA exporter influencing root morphology and seed germination of Medicago truncatula. The Plant Journal, Oxford, v. 98, p. 511-523, 2019.

PEREIRA, K. T. O. et al. Germinação e vigor de sementes de Moringa oleifera Lam. em diferentes substratos e temperaturas. Revista Caatinga, Mossoró, v. 28, n. 2, p. 92-99, 2015.

PEREIRA, M. C. et al. Germinação de sementes de melão-de-são-caetano sob variação de água, luz e temperatura. Bioscience Journal, Uberlândia, v. 27, n. 3, p. 363-370, 2011.

PERES, A. L. G. L. et al. Brassinosteroids, the sixth class of phytohormones: a molecular view from the discovery to hormonal interactions in plant development and stress adaptation. International journal of molecular sciences, Basel, v. 20, n. 2, p. 331, 2019.

POLESI, L. G. et al. Chloroplast ultrastructure and hormone endogenous levels are differently affected under light and 
MEIRA, K. S. et al. Morfometria radicular de Moringa oleifera em função do pré-tratamento de sementes com luz e extrato de tiririca. In: II Congresso Paraibano de Agroecologia \& IV Exposição Tecnológica, 2019. Anais... Caderno Verde de Agroecologia e Desenvolvimento Sustentável, Pombal, v. 9, n.7, e-7058, 2019.

dark conditions during in vitro culture of Guadua chacoensis (Rojas) Londoño \& PM Peterson. Acta Physiologiae Plantarum, Krakow, v. 41, n. 1, p. 10, 2019.

RIFNA, E. J.; RAMANAN, K. R.; MAHENDRAN, R. Emerging technology applications for improving seed germination. Trends in Food Science \& Technology, Norwich, v. 86, p. 95- 108, 2019.

SANO, N.; SEO, M. Cell cycle inhibitors improve seed storability after priming treatments. Journal of plant research, Sendai, v. 132, n. 2, p. 263-271, 2019.

SHAPIRO, S. S.; WILK, M. B. An Analysis of Variance Test for Normality (Complete Samples). Biometrika Trust, Oxford, v. 52, p. 591-609, 1965.

SILVA, A. E. et al. Microclimate changes, photomorphogenesis, and water consumption by Moringa oleifera cuttings under light spectrum variations and exogenous phytohormones concentrations. Australian Journal of Crop Science, Queensland, 2019. No prelo.

SIMÕES, C. M. O. et al. Farmacognosia: da planta ao medicamento. 5. ed. Florianópolis: Ed. Da UFSC, p. 1102, 2003.

SMALL, C. C.; DEGENHARDT, D. Plant growth regulators for enhancing revegetation success in reclamation: A review. Ecological Engineering, Oxford, v. 118, p. 43-51, 2018.

TSUCHIDA-MAYAMA, T. et al. Role of the phytochromo and cryptochrome signaling pathways in hypocotyl phototropism. The Plant Journal, Oxford, v. 62, p. 653-662, 2010.

TUAN, P. A. et al. 1 - Molecular mechanisms of seed germination. In: TUAN, P. A. et al. Sprouted Grains. AACC International Press, p. 1-24, 2019.

VAISHAK, K. P. et al. The B-box bridge between light and hormones in plants. Journal of Photochemistry and Photobiology B: Biology, Quebec, v. 191, p. 164-174, 2019.

WEBER, S. et al. Anthocyanin synthesis and light utilisation can be enhanced by reflective mulch Visualisation of light penetration into a tree canopy. Journal of Plant Physiology, Amsterdã, v. 233, p. 52-57, 2019.

\section{AGRADECIMENTOS}

Apoio financeiro: Fundação de Apoio à Pesquisa do Estado da Paraíba - FAPESQ. 